\title{
Total Factor Productivity Growth, Technical Progress \& Efficiency Change in Vietnam Coal Industry - Nonparametric Approach
}

\author{
$V u$ Hung Phuong ${ }^{1, *}$ \\ ${ }^{1}$ National Economics University, Vietnam
}

\begin{abstract}
This research applies Data Envelopment Analysis (DEA) approach to analyze Total Factor Productivity (TFP) and efficiency changes in Vietnam coal mining industry from 2007 to 2013. The TFP of Vietnam coal mining companies decreased due to slow technological progress and unimproved efficiency. The decadence of technical efficiency in many enterprises proved that the coal mining industry has a large potential to increase productivity through technical efficiency improvement. Enhancing human resource training, technology and research \& development investment could help the industry to improve efficiency and productivity in Vietnam coal mining industry. Key words - Technical \& Scale Efficiency; Total Factor Productivity-TFP; Nonparametric Techniques.
\end{abstract}

\section{Introduction}

Total merchandise coal production in the 20 years was 525 million tons, of which the highest yearly production is 44.7 million tons in 2011, equaling 7.5 times of that in 1995 when Vietnam Coal Corporation was established. Since 2012, due to the effects of financial crisis and economic downturn in the country and all over the world, the business efficiency of the Vinacomin has much decreased compared to 2011, but production, employment and income for workers have remained stable. Overall labor productivity in 2011 (when Vietnam coal mining industry reached the highest production so far) was 4 times that in 2011 (merchandise coal production increased from 6 million tons to 45 million tons, an increase of 7.5 times, while the number of employees only increased by 1.8 times). However, after 2011, labor productivity not increased because of several reasons: proportion of coal exploited by mine tunnel technology has been increasingly raised (labor expense in tunnel technology is much higher than that in open-cast mine), from 2011 to 2015 proportion of tunnel coal increased from 45 to $56 \%$; production output has been constrained by market, while some steps in mining process must be maintained to preserve mine tunnels (particularly ventilation, drainage, etc.); gravelly soil volume that needs to be removed in open-cast mine has increased because mines have been increasingly deeper, investment in mechanization has been limited, investment projects has been late in progress, etc.

* Corresponding author: hungphuongvu@yahoo.com 
Since Vietnam economy reform started in 1986, the influence of these reforms on productivity and efficiency of coal mining industry has been cared about and investigated by many researchers, economic and enterprise managers. Prior studies suggested that institution changes are an essential cause of the increase in productivity of coal mining industry in the reform period. In these studies, effects of technological changes were either ignored or considered as insignificant.

Most of the studies on coal mining industry productivity followed the traditional parameter approach to calculate total factor productivity by estimating an aggregate production function, a cost function, or a profit function. However, the traditional parameter methods are distrusted by many economists because of their aggregate hypotheses.

Large coal mining companies listed in Enterprise survey from 2000-2014 were sampled in the research. These companies are members of Vietnam National Coal-Mineral under State owned monopoly. However, the research only analyzes TFP, technology and efficiency changes in coal mining in Vietnam from Asian financial crisis in 2007.

This research adopts a data envelopment analysis (DEA) approach to investigate total factor productivity (TFP) growth in coal mining industry of Vietnam from 2007 to 2014. Using Malmquist productivity index), the TFP increase in the coal industry is decomposed into technical and efficiency changes [2]. The technical change enables them to identify contributions of improved technical productivity and technological progress to productivity growth of coal mining industry.

In Vietnam, the nonparametric method was developed to decompose TFP change in provincial agriculture of Vietnam into changes in technological progress and efficiency change [5].

Besides nonparametric method mentioned above, there exists stochastic frontier production function method to decompose total factor productivity change into changes in technological progress and efficiency.

\section{Methodology}

\subsection{Measuring total factor productivity: Malmquist indices}

In order to define the Malmquist index of productivity change we consider, for each time period $t=1,2, \ldots, T$, a production technology $H^{t} S^{t}$ for changing inputs, $x^{t} \in \mathrm{R}_{+}^{\mathrm{N}}$, into outputs, $y^{t} \in \mathrm{R}_{+}^{\mathrm{M}}$, is defined as:

$$
H^{t}=\left\{\left(x^{t}, y^{t}\right): x^{t} \text { can produce } y^{t}\right\}
$$

where $H^{t}$ is assumed to satisfy certain axioms to define significant output distance functions (Făre, 1988).

According to Făre et al. (1994), an output distance function at $t$ can be defined as

$$
D_{0}^{t}\left(x^{t}, y^{t}\right)=\inf \left[\theta:\left(x^{t}, y^{t} / \theta\right) \in H^{t}\right]=\left\{\sup \left[\theta:\left(x^{t} \theta y^{t}\right) \in H^{t}\right]\right\}^{-1}
$$

The distance function is defined as the inverse of maximum proportional increase of output vector $y^{t}$ given inputs $X^{t}$. It is also equivalent to inverse of output efficiency measure, measure of TFP "catch-up" of an observation (an enterprise in this study) with the best practice frontier in coal mining, in this study, the best practice frontier is the highest productivity observed in all enterprises with the same technology [4]. $D_{0}^{t}\left(x^{t}, y^{t}\right)=1$ if and 
only if $\left(x^{t}, y^{t}\right)$ is on the boundary or the frontier of technology and the production is technologically efficient. If $D_{0}^{t}\left(x^{t}, y^{t}\right)<1$, the production is inside the technological frontier at $t$, and $\left(x^{t}, y^{t}\right)$ is technologically inefficient. The distance function measures the degree of technical inefficiency. The output distance in the period $t+1, D^{t+1}\left(x^{t}, y^{t}\right)$, can be defined as (2) with t replaced by $t+1$.

Definition of output distance function with two different time periods is

$$
D_{0}^{t}\left(x^{t+1}, y^{t+1}\right)=\inf \left\{\theta:\left(x^{t+1} / \theta\right) \in H^{t}\right\}
$$

This is a mixed index measuring maximum proportional changes in outputs $y^{t+1}$ given inputs $x^{t+1}$, under technology at $t$. Similarly, we can define a mixed distance function, $D^{t+1}\left(x^{t}, y^{t}\right)$, measuring maximum proportional changes in output $y^{t}$, given inputs $x^{t}$, under technology at $t+1$.

According to Caves et al. (1982a), Malmquist productivity index is defined as

$$
M_{0}^{t}=\frac{D_{0}^{t}\left(x^{t+1}, y^{t+1}\right)}{D_{0}^{t}\left(x^{t}, y^{t}\right)}
$$

This ratio index measures productivity changes originated from changes in technical efficiency at $t$ and $t+1$ under technology at $t$. Changes in technical efficiency from $t$ to $t+1$ also can be measured under technology at $t+1$. This Malmquist index is defined as

$$
M_{1}^{t+1}=\frac{D_{1}^{t+1}\left(x^{t+1}, y^{t+1}\right)}{D_{1}^{t+1}\left(x^{t}, y^{t}\right)}
$$

Output oriented Malmquist productivity change index can be specified as the geometric average of (4) and (5) and decomposed into two components:

$$
\begin{aligned}
M_{0}\left(x^{t+1}, y^{t+1}, x^{t}, y^{t}\right) & =\left\{\left[\frac{D_{0}^{t}\left(x^{t+1}, y^{t+1}\right)}{D_{0}^{t}\left(x^{t}, y^{t}\right)}\right]\left[\frac{D_{1}^{t+1}\left(x^{t+1}, y^{t+1}\right)}{D_{1}^{t+1}\left(x^{t}, y^{t}\right)}\right]\right\}^{1 / 2}= \\
& =\frac{D_{1}^{t+1}\left(x^{t+1}, y^{t+1}\right)}{D_{0}^{t}\left(x^{t}, y^{t}\right)}\left\{\left[\frac{D_{0}^{t}\left(x^{t+1}, y^{t+1}\right)}{D_{1}^{t+1}\left(x^{t+1}, y^{t+1}\right)}\right]\left[\frac{D_{0}^{t}\left(x^{t}, y^{t}\right)}{D_{1}^{t+1}\left(x^{t}, y^{t}\right)}\right]\right\}^{1 / 2}= \\
& =E\left(x^{t+1}, y^{t+1}, x^{t}, y^{t}\right) T\left(x^{t+1}, y^{t+1}, x^{t}, y^{t}\right)
\end{aligned}
$$

where $E(*)$ is relative efficiency change index under constant return-to-scale technology, measuring catching up with the best practice frontier for each observation between periods $t$ and $t+1$, and $T\left(^{*}\right)$ expresses technical change index, measuring technological frontier shift (or innovation) between the two periods evaluated at $x^{t}$ and $x^{t+1}$.

Decomposition of Malmquist productivity index enables us to identify the contribution of efficiency catching up and technology innovation to total factor productivity growth. The Malmquist index greater than 1 indicates an increase in productivity. The Malmquist index less than 1 indicates a decrease in productivity. In addition, increases in any of the two components of Malmquist productivity index are connected with values greater than 1 , and any its decreases are connected with values less than 1 . 


\subsection{Intermediate Problems - Data Envelopment Analysis (DEA)}

Some conventional methods were listed for calculating Malmquist productivity index [3]. Most of them, however, require specification of a functional form of technology. A data envelopment analysis approach (DEA) was proposed to build a best practice frontier without specification of production technology. Unlike conventional analysis techniques that look for an average path through middle points of data series, DEA seeks directly a best practice frontier with these data. Using a nonparametric linear programming technique, DEA takes account of all inputs and outputs as well as differences in technology, ability, competitiveness and population, and compares individual performance to the best practice (efficient) frontier [2].

In this research, a DEA approach developed by Făre et al. is used to construct a best practice frontier for each technology categories at each period in the coal industry. Comparison of exploited volumes of each enterprise with the best practice frontier provides a measure of catch-up in its efficiency with that frontier and a measure of the shift of that frontier (or technology innovation). Then, Malmquist index, which measures changes in total factor productivity, can be computed as a product of these components.

Assume that there are $k=1, \ldots, K$ provinces producing $m=1, \ldots, M$ outputs $y_{k, m}^{t}$ using $n=1, \ldots, N$ inputs $x_{k, n}^{t}$ at each period $t=1, \ldots, T$. In DEA approach, reference technology with constant return-to-scale at each period $t$ from data can be defined as

$$
\begin{array}{ll}
G^{t}=\left(x^{t}, y^{t}\right): y_{m}^{t} \leq \sum_{k=1}^{K} Z_{k}^{t} y_{k, m}^{t} & m=1, \ldots, M, \\
\sum_{k=1}^{K} Z_{k}^{t} x_{k, n}^{t} \leq x_{n}^{t} & n=1, \ldots, N, \\
z_{k}^{t} \geq 0 & k=1, \ldots, K
\end{array}
$$

where $\mathrm{z}$ indicates weights on each cross-sectional observation. Constant return-to-scale assumption can be relaxed by adding the following constraint [1]:

$$
\sum_{k=1}^{K} Z_{k}^{t}=1, \quad(V R S)
$$

We use a higher decomposition of Malmquist index to analyze productivity growth of the coal industry in Vietnam. We decompose efficiency change component, which is calculated under constant return-to-scale technology, into a pure efficiency change component (which is calculated under variable return-to-scale technology-VRS) and a component of scale change capturing different internal changes between variable return-to-scale technology and constant return-to-scale technology.

To construct Malmquist productivity index of enterprise $\mathrm{k}$ ' between $\mathrm{t}$ and $\mathrm{t}+1$, we use DEA approach to compute four distance functions $D_{0}^{t}\left(x^{t}, y^{t}\right), D_{0}^{t+1}\left(x^{t}, y^{t}\right), D_{0}^{t}\left(x^{t+1}, y^{t+1}\right)$ and $D_{1}^{t+1}\left(x^{t+1}, y^{t+1}\right)$. These distance functions are inverses of Farrell technical efficiency measures. Non-parametric programming models to calculate output-oriented measure of technological efficiency for each province $k^{\prime}=1, \ldots, K$, can be defined as

$$
\left[D_{0}^{t}\left(x_{k}^{t}, y_{k}^{t}\right)\right]^{-1}=\max \lambda^{k}
$$




$$
\begin{array}{ll}
\lambda^{k^{\prime}} y_{k^{\prime}, m}^{t} \leq \sum_{k=1}^{K} z_{k}^{t} y_{k, m}^{t}, & m=1, \ldots, M, \\
\sum_{k=1}^{K} z_{k}^{t} x_{k, n}^{t} \leq x_{k^{\prime}, n}^{t} & n=1, \ldots, N, \\
z_{k}^{t} \geq 0 & k=1,2, \ldots, K
\end{array}
$$

Calculation of $\left[D_{0}^{t+1}\left(x^{t+1}, y^{t+1}\right)\right]$ is similar to (10), in which $t$ is replaced by $t+1$.

Construction of Malmquist Index also requires calculating two mixed distance functions, calculated by comparing observations in one period with the best practice frontier of another period. The inverse of the mixed distance function for observation $k^{\prime}$ can be obtained from

$$
\left[D_{0}^{t}\left(x_{k}^{t+1}, y_{k}^{t+1}\right)\right]^{-1}=\max \lambda^{k}
$$

subject to

$$
\begin{array}{ll}
\lambda^{k^{\prime}} y_{k^{\prime}, m}^{t+1} \leq \sum_{k=1}^{K} z_{k}^{t} y_{k, m}^{t}, & m=1, \ldots, M, \\
\sum_{k=1}^{K} z_{k}^{t} x_{k, n}^{t} \leq x_{k^{\prime}, n}^{t+1} & n=1, \ldots, N, \\
z_{k}^{t} \geq 0 & k=1,2, \ldots, K
\end{array}
$$

To gauge changes in scale efficiency, inversed output distance functions with variable return-to-scale technology are calculated by adding (8) into constraints (10) and (12). Technological change (TECHCH) is calculated under constant return-to-scale technology. Scale efficiency change ( $\mathrm{SCH})$ at each period is constructed as the ratio of the distance function with constant return-to-scale to the distance function under variable return-to-scale technology, while pure efficiency change (PEFFCH) is defined as the ratio of distance functions at each period under variable return-to-scale technology. With these two distance functions under variable return-to-scale technology, decomposition of (6) becomes

$$
\begin{aligned}
M_{0}\left(x^{t+1}, y^{t+1}, x^{t}, y^{t}\right) & =T\left(x^{t+1}, y^{t+1}, x^{t}, y^{t}\right)= \\
& =T E C H C H \cdot E F F C H= \\
& =T E C H C H \cdot P E F F C H \cdot S C H
\end{aligned}
$$

where EFFCH denotes efficiency change calculated under constant return-to-scale technology.

\section{Estimated results and decomposition of total factor productivity (TFP)}

As indicated by [3], the distance function is equivalent to the inverse of Farrell measure of output efficiency. We use this index, defined as the inverse of (2), to measure the technological efficiency of enterprises in the coal industry in the period 2007-2013. Technical efficiency indices under the return-toscale variables of 29 enterprises from 2007 to 2013 are reported in Table 1. 
Table 1. Technical efficiency indices under variable return-to-scale of coal mining enterprises, 2007-2013

\begin{tabular}{|c|c|c|c|c|c|}
\hline & $\begin{array}{c}\text { Number of } \\
\text { Observations }\end{array}$ & Mean & $\begin{array}{c}\text { Standard } \\
\text { Deviation }\end{array}$ & Min & Max \\
\hline crste2007 & 29 & 0.3308 & 0.2601 & 0.01 & 1 \\
\hline vrste2007 & 29 & 0.5861 & 0.2711 & 0.122 & 1 \\
\hline scale2007 & 29 & 0.6069 & 0.3353 & 0.015 & 1 \\
\hline crste2009 & 29 & 0.5511 & 0.3327 & 0.063 & 1 \\
\hline vrste2009 & 29 & 0.7449 & 0.2898 & 0.22 & 1 \\
\hline scale2009 & 29 & 0.7512 & 0.3100 & 0.07 & 1 \\
\hline crste2011 & 29 & 0.2921 & 0.2663 & 0.002 & 1 \\
\hline vrste2011 & 29 & 0.6414 & 0.2883 & 0.037 & 1 \\
\hline scale2011 & 29 & 0.4584 & 0.3326 & 0.004 & 1 \\
\hline crste 2013 & 29 & 0.5046 & 0.2915 & 0.028 & 1 \\
\hline vrste2013 & 29 & 0.6754 & 0.2699 & 0.127 & 1 \\
\hline scale2013 & 29 & 0.7328 & 0.2702 & 0.055 & 1 \\
\hline
\end{tabular}

where:

- crste: Technical efficiency under constant return-to-scale hypothesis,

- vrste: Pure technical efficiency under variable return-to-scale hypothesis,

- scale: Scale efficiency.

Source: Author's calculations from Enterprise Survey data 2007-2014. General Statistic Office

Table 1 shows averages of efficiency under constant return-to-scale, variable return-toscale and scale efficiency of sample enterprises in the coal industry and reports only estimates of these efficiency measures for 4 years: 2007, 2009, 2011 and 2013. The results display strong fluctuations of efficiency measures. For instance, averages of efficiency under constant return-to-scale in 2007, 2009, 2011 and 2013 are 0.3308, 0.5511, 0.2921, 0.5046, respectively. In general, all efficiency indices show that performance of enterprises in the industry is still inefficient. The highest scale efficiency (in 2009) reached only $75.12 \%$.

Table 2. Annual average changes of Malmquist indices, 2007-2013

\begin{tabular}{|c|c|c|c|c|c|}
\hline Year & Effch & Techch & Pech & Sech & Tfpch \\
\hline $2007-2008$ & 1.032 & 0.84 & 1 & 1.032 & 0.867 \\
\hline $2008-2009$ & 0.944 & 0.869 & 1 & 0.944 & 0.82 \\
\hline $2009-2010$ & 1.183 & 0.722 & 1 & 1.183 & 0.854 \\
\hline $2010-2011$ & 1.121 & 0.906 & 1 & 1.121 & 1.015 \\
\hline $2011-2012$ & 0.723 & 1.241 & 1 & 0.723 & 0.898 \\
\hline $2012-2013$ & 1.847 & 0.525 & 1 & 1.847 & 0.97 \\
\hline Average & 1.095 & 0.823 & 1 & 1.095 & 0.901 \\
\hline
\end{tabular}

where:

- Effch: Efficiency change

- Pech: Pure efficiency change

- Tfpch: Total factor productivity change

- Techch: Technological change

- Sech: Scale efficiency change

Source: Author's calculations from Enterprise Survey data 2007-2014. General Statistic Office

Table 2 shows results of decomposition of total factor productivity in the coal industry in the sample. The average efficiency change of this period increased (1.095), but there were 2 stages with low efficiency change, namely in 2008-2009 (reached only 94.4\%) and especially in 2011-2012 with even average efficiency change decreased (reached only $72.3 \%$ ). Technological 
changes decrease in general, reached only $82.3 \%$ in $2007-2013$. The total factor productivity change in this period was low, reached only $90.1 \%$. The main cause of TFP decreased was a very low level of application of technical innovation and new technology.

The year 2011 was the year with the highest TFP in the studied period, it reached 1.015. This estimated result was in accord with the report on performance of the industry in 20 years. According to the report, total merchandise coal production in 2011 reached the highest level, which equals 7.5 times of the level of the year of establishment of Vietnam Coal Corporation in 1995.

The reason for labor productivity growth of the coal industry in this stage was liberalization of production capacity by reasonable rearrangement of organization model in coal firms, application of new mining technologies, adoption of contractual mechanisms which created motivation and spring forces for labor productivity. Another equally important reason is the high growth of coal market in the period 2007-2011 which stimulated production.

The question why total factor productivity in the coal industry decreased (except for 2011) can be explained as follows: (1) Exploitation activities of coal mining industry are different from production in factories, mining has been shifting deeper and further day by day into the earth's womb, gravelly soil volume that needs to be removed in both open-cast mine and tunneling, transport distance increased (for 1 ton of exploited coal, gravelly soil volume that needs to be removed increased 3.1 times from $3.4 \mathrm{~m}^{3} /$ ton in 1995 to $10.7 \mathrm{~m}^{3} /$ ton in 2014, transport distance increased 3.72 times from $1.03 \mathrm{~km}$ in 1995 to $3.83 \mathrm{~km}$ in 2014 , these two factors caused exploitation cost increase 5 times), high mine pressure, big volume of air and water,... made ventilation, drainage and transportation costs highly increase... (2) Competition has been increasingly severe; (3) Demand for coal is one of the important factors; (4) Exploitation technology can be not really advanced yet; (5) There are still many inadequacies in management...

\section{Summary and conclusion}

This study applies DEA approach to measure total factor productivity (TFP), technical change and technological efficiency in Vietnam coal mining industry from 2007 to 2013. Malmquist productivity index is used to measure productivity growth in this study. With data envelopment analysis approach (DEA), productivity growth can be decomposed into two components: Technical change and efficiency change. This decomposition enables us to identify contributions of technical progress and improvement in technical efficiency to productivity growth in coal production.

In the study, data envelopment analysis method (DEA) is used to calculate component distance functions of Malmquist index and construct the best practice frontiers. Technical change index and efficiency change index is obtained by comparing the efficiency of each enterprise to the best practice frontier with the same production technology. Then Malmquist productivity index is calculated as the product of these indices.

Calculated results show that change in TFP of the coal industry decreased, the main reason is that investment in technological progress of the industry is still low, or asynchronous, or inefficient, except for 2011 which is the year with high productivity growth due to increased demand stimulating production.

Policy recommendations: To raise efficiency, TFP growth, it is necessary:

1) To enhance qualification of management staff;

2) To raise technical level of workers and technical staff, enable them to stabilize their life and keep their mind on their work;

3) To strengthen technological innovation to improve productivity;

4) To implement well marketing activities, expand into new markets and maintain traditional markets; 
5) To enhance competitiveness by cost reduction via good management and technical application, technological improvement.

\section{References}

1. S.N. Afriat, Efficiency Estimation of Production Functions, International Economic Review 13, 568-98 (1972)

2. A. Charnes, W.W. Cooper and E. Rhodes, Measuring the efficiency of decision making units, European Journal of Operational Research 2, 429-444 (1978)

3. R. Färe, S. Grosskopf and C.A.K. Lovell, Production frontiers (Cambridge University Press, Cambridge) (1994)

4. M.J. Farrell, The measurement of productive efficiency, Journal of the Royal Statistical Society, Series A (General) 120, 253-289 (1957)

5. Nguyen Khac Minh \& Pham Van Khanh, A chance-constrained data envelopment analysis approach to problem provincial productivity growth in Vietnamese agriculture from 1995 to 2007, Open Journal of Statistics, 1, 217-235 (2011)

6. Vietnam Coal-Mineral Group, Solutions to Increase Production and Efficiency in Period 2015-2020, Internal report (2016) 